\title{
Retrieval of aerosol parameters from the oxygen A band in the presence of chlorophyll fluorescence
}

\author{
A. F. J. Sanders and J. F. de Haan \\ Royal Netherlands Meteorological Institute (KNMI), De Bilt, the Netherlands \\ Correspondence to: A. F. J. Sanders (bram.sanders@knmi.nl) \\ Received: 15 February 2013 - Published in Atmos. Meas. Tech. Discuss.: 2 April 2013 \\ Revised: 3 September 2013 - Accepted: 3 September 2013 - Published: 18 October 2013
}

\begin{abstract}
We have investigated the precision of retrieved aerosol parameters for a generic aerosol retrieval algorithm over vegetated land using the $\mathrm{O}_{2}$ A band. Chlorophyll fluorescence is taken into account in the forward model. Fluorescence emissions are modeled as isotropic contributions to the upwelling radiance field at the surface and they are retrieved along with aerosol parameters. Precision is calculated by propagating measurement errors and a priori errors, including model parameter errors, using the forward model's derivatives. Measurement errors consist of noise and calibration errors. The model parameter errors considered are related to the single scattering albedo, surface pressure and temperature profile. We assume that measurement noise is dominated by shot noise; thus, results apply to grating spectrometers in particular. We describe precision for various atmospheric states, observation geometries and spectral resolutions of the instrument in a number of retrieval simulations. These precision levels can be compared with user requirements. A comparison of precision estimates with the literature and an analysis of the dependence on the a priori error in the fluorescence emission indicate that aerosol parameters can be retrieved in the presence of chlorophyll fluorescence: if fluorescence is present, fluorescence emissions should be included in the state vector to avoid biases in retrieved aerosol parameters.
\end{abstract}

\section{Introduction}

Chlorophyll in terrestrial vegetation exhibits fluorescence in the red and near-infrared wavelength range. The oxygen A band at $760 \mathrm{~nm}$ is located in the fluorescence wavelength region and is often used for cloud retrieval (e.g., Fast REtrieval
Scheme for Clouds from the Oxygen A band (FRESCO): Koelemeijer et al., 2001; Semi-Analytical CloUd Retrieval Algorithm (SACURA): Rozanov and Kokhanovsky, 2004) and also increasingly for aerosol retrieval. Current and future operational algorithms employ the $\mathrm{O}_{2} \mathrm{~A}$ band for retrieval of aerosol parameters per se (e.g., Sanders et al., 2012; Dubuisson et al., 2012) or for aerosol correction as part of a more convolved trace gas retrieval (e.g., O’Dell et al., 2012; Butz et al., 2012; Reuter et al., 2010; Yoshida et al., 2011). Recently, advancements in the remote sensing of fluorescence emissions from space using hyperspectral radiance measurements have been made (Frankenberg et al., 2011a; Joiner et al., 2011, 2012b, 2013; Guanter et al., 2012). If the relatively small fluorescence signal is strong enough to enable fluorescence retrieval from space, the question arises as to whether fluorescence emissions will interfere with aerosol retrieval from the $\mathrm{O}_{2}$ A band and, if so, of how to account for fluorescence in an aerosol retrieval algorithm.

A number of previous studies have investigated the potential of the $\mathrm{O}_{2}$ A band for retrieval of aerosol parameters.. Early papers discussing aerosol retrieval from the $\mathrm{O}_{2} \mathrm{~A}$ band are by Badayev and Malkevich (1978) and Gabella et al. (1999). Corradini and Cervino (2006) have presented a simulation study of retrieval of the extinction profile for instrument characteristics of the SCanning Imaging Absorption spectroMeter for Atmospheric CHartographY (SCIAMACHY: Bovensmann et al., 1999). Actual case studies using hyperspectral $\mathrm{O}_{2} \mathrm{~A}$ band measurements have been performed by Koppers and Murtagh (1997) using data from the Global Ozone Monitoring Experiment (GOME: Burrows et al., 1999), and by Kokhanovsky and Rozanov (2010) and Sanghavi et al. (2012) using data from SCIAMACHY. Koppers and Murtagh (1997) have retrieved surface albedo 
simultaneously with aerosol optical thickness and height distribution, while in the retrievals proposed by Kokhanovsky and Rozanov (2010) and Sanghavi et al. (2012) the surface albedo basically is a model parameter (i.e., surface albedo not fitted). Sensitivity studies to consolidate instrument requirements for $\mathrm{O}_{2}$ A band aerosol retrieval include studies for the Sentinel-4/5 missions (Ingmann et al., 2012) by Siddans et al. (2007) and Hasekamp and Siddans (2009). Sanders et al. (2012) prepare for aerosol layer height retrieval with the TROPOspheric Monitoring Instrument (TROPOMI: Veefkind et al., 2012) on the Sentinel-5 Precursor mission. In none of these studies is the role of fluorescence emissions in retrieval of aerosol parameters discussed.

Furthermore, there are indications that the FRESCO cloud retrieval algorithm also provides information on aerosols when there are optically thick aerosol layers (Wang et al., 2012). Dubuisson et al. (2009) have presented a method to retrieve the altitude of aerosol plumes over ocean from the ratio of reflectances in the two $\mathrm{O}_{2} \mathrm{~A}$ band channels of the MEdium Resolution Imaging Spectrometer (MERIS: Rast et al., 1999) instrument and the POLarization and Directionality of the Earth's Reflectance (POLDER: Deschamps et al., 1994) instrument. Finally, we mention the work by Van Diedenhoven et al. (2005) which showed that retrieved apparent surface pressure (i.e., retrieved surface pressure when ignoring aerosol scattering) with SCIAMACHY depends systematically on aerosol parameters. This illustrates in yet another way that the $\mathrm{O}_{2} \mathrm{~A}$ band contains aerosol information available for retrieval.

Photosynthesis in chlorophyll pigments is driven by the absorption of visible solar radiation between approximately 400 and $700 \mathrm{~nm}$ (photosynthetically active radiation). Part of the energy absorbed by chlorophyll that is not used for carbon fixation is re-emitted at longer wavelengths in the 650 to $800 \mathrm{~nm}$ wavelength range (fluorescence). Interest in remote sensing of solar-induced chlorophyll fluorescence arises because it is an indicator of photosynthetic activity (e.g., Maxwell and Johnson, 2000; Krause and Weis, 1991). Frankenberg et al. (2011b) have indeed shown a strong linear correlation between satellite retrievals of fluorescence and gross primary production from vegetation models. Satellitebased remote sensing of fluorescence would thus offer a way to measure carbon fluxes associated with gross primary production on a global scale.

For the present study, it is important to know typical values of fluorescence emissions at the $\mathrm{O}_{2} \mathrm{~A}$ band. Guanter et al. (2012) retrieved fluorescence emissions at $755 \mathrm{~nm}$, which is near the start of the $\mathrm{O}_{2} \mathrm{~A}$ band, using measurements from the Greenhouse gases Observing SATellite (GOSAT: Kuze et al., 2009). They reported monthly $2^{\circ}$ by $2^{\circ}$ average values up to $1.8 \mathrm{~mW} \mathrm{~m}^{-2} \mathrm{sr}^{-1} \mathrm{~nm}^{-1}$. This range agrees with Frankenberg et al. (2011b), who also used GOSAT measurements but employed a different retrieval method. Around the $\mathrm{O}_{2} \mathrm{~A}$ band, fluorescence emissions typically decrease with wavelength. Laboratory measurements of leaf fluorescence as well as leaf and canopy models show that emissions at $770 \mathrm{~nm}$ can be smaller than emissions at $755 \mathrm{~nm}$ by up to a factor of 2 (e.g., Amoros-Lopez et al., 2008; Guanter et al., 2010). A linear wavelength dependence seems sufficient to describe the spectral behavior across the $\mathrm{O}_{2} \mathrm{~A}$ band.

Fluorescence emissions are a slowly varying function of wavelength. There are basically two mechanisms for retrieving fluorescence emissions from space: the filling-in of Fraunhofer lines and the filling-in of atmospheric absorption bands (e.g., oxygen bands). The filling-in of atmospheric absorption bands occurs because photons emitted at the surface pass the atmosphere only once, whereas photons reflected by the surface pass the atmosphere twice before reaching the detector. These mechanisms make it, in principle, possible to distinguish light reflected by the atmosphere-surface from fluorescence emissions. Figure 1 shows monochromatic reflectance spectra and simulated measurements at a spectral resolution of 0.1 and $0.5 \mathrm{~nm}$. The atmosphere contains aerosols (aerosol optical thickness at $760 \mathrm{~nm}$ of 0.4 and a layer pressure of $700 \mathrm{hPa}$ ) over vegetated land (albedo of 0.20 at $758 \mathrm{~nm}$ ) with a representative fluorescence emission $\left(1.2 \mathrm{~mW} \mathrm{~m}^{-2} \mathrm{sr}^{-1} \mathrm{~nm}^{-1}\right.$ at $\left.758 \mathrm{~nm}\right)$. Simulated measured reflectance spectra in the right panel of Fig. 1 correspond to retrievals in Fig. 4; for details of these simulations, see Sect. 4.2. Note that for this representative scenario the increase in continuum reflectance (hence in radiance) due to the fluorescence emission is about $2 \%$.

Frankenberg et al. (2011a) have shown that if fluorescence is not taken into account (i.e., zero emissions assumed in retrieval, emissions not fitted), significant biases in retrieved aerosol parameters (optical thickness, height of the Gaussian layer), surface albedo and surface pressure occur. We have confirmed this finding: for the forward model described in Sect. 2 we find aerosol pressure biases up to $100 \mathrm{hPa}$ and biases in optical thickness up to 2.0 as well as non-convergent retrievals. Apparently, errors in aerosol and fluorescence parameters are correlated, and so part of the fit residue caused by ignoring fluorescence is absorbed by other retrieval parameters. This finding, however, does not yet prove that it is actually impossible to retrieve aerosol and fluorescence parameters simultaneously.

Even if derivatives are to some extent linearly dependent, which they are in this case as well as in many other retrieval problems, parameters may still be fitted with acceptable precision levels. Figure 2 shows normalized derivatives (i.e., normalized to 1.0 at their respective maximum) of reflectance with respect to surface albedo, aerosol optical thickness, aerosol mid pressure and fluorescence emission. Derivatives are calculated at a spectral resolution of $0.5 \mathrm{~nm}$ for the same atmospheric scenario as in Fig. 4 except that the surface albedo and fluorescence emission here are assumed to be independent of wavelength for ease of interpretation. Overall, one can see that particularly spectral shapes of derivatives with respect to surface albedo and fluorescence emission are similar, although there are small differences in 

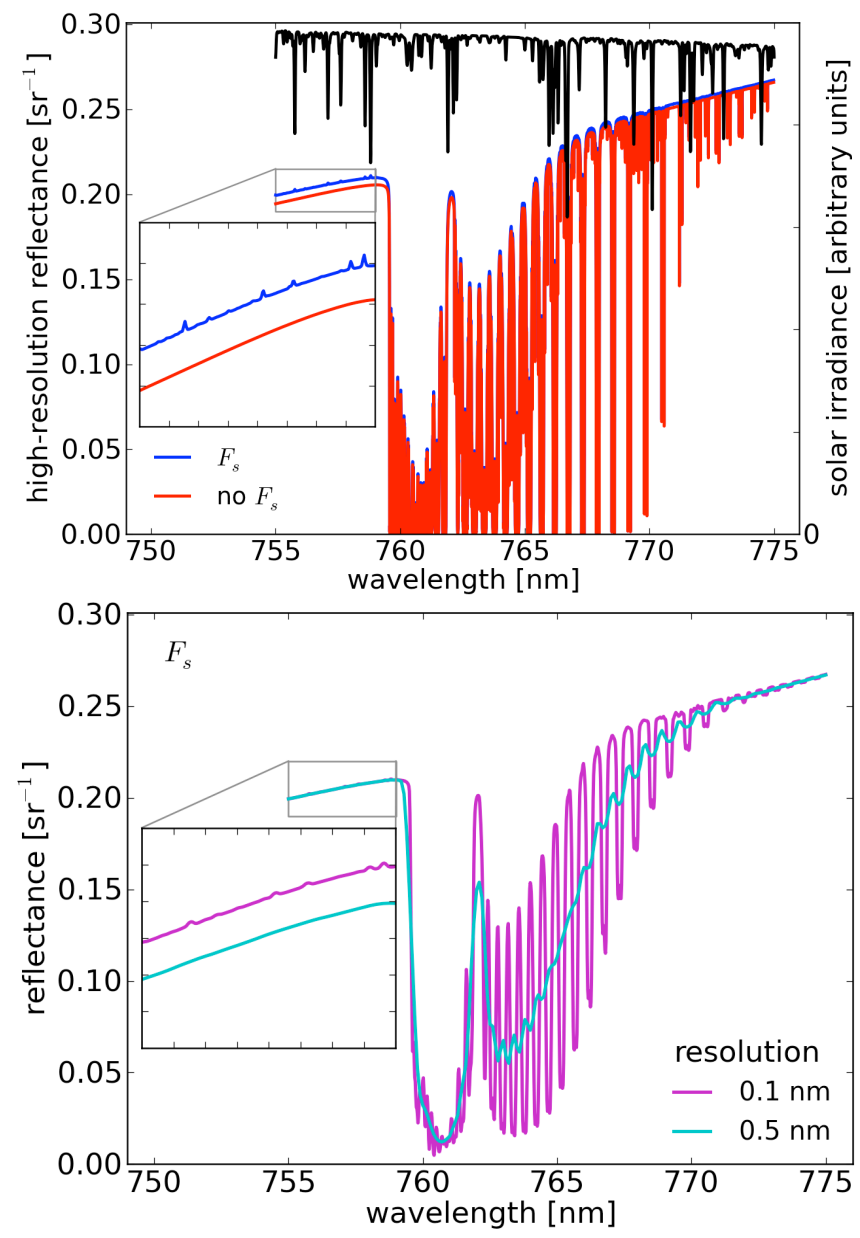

Fig. 1. Left panel: high-resolution reflectance spectrum (left $y$ axis) with fluorescence emission (" $F_{\mathrm{S}}$ ": blue line) and without fluorescence emission ("no $F_{\mathrm{S}}$ ": red line), and a high-resolution solar irradiance spectrum (right $y$ axis, black line). Right panel: the highresolution reflectance spectrum containing fluorescence emission of the left panel after convolution with the slit function at resolutions (full width at half maximum) of $0.1 \mathrm{~nm}$ (magenta line) and $0.5 \mathrm{~nm}$ (cyan line). The atmosphere contains aerosols ( $\tau$ of 0.4 at the $\mathrm{O}_{2} \mathrm{~A}$ band and $P_{\text {mid }}$ of $700 \mathrm{hPa}$ with a layer thickness of 100 $\mathrm{hPa}$ ) over vegetated land ( $A_{\mathrm{S}}$ linearly sloping upward from 0.20 at $758 \mathrm{~nm}$ to 0.25 at $770 \mathrm{~nm}$ ) with a representative fluorescence emission $\left(F_{\mathrm{S}}\right.$ linearly sloping downward from $1.2 \mathrm{~mW} \mathrm{~m}^{-2} \mathrm{sr}^{-1} \mathrm{~nm}^{-1}$ to $0.6 \mathrm{~mW} \mathrm{~m}^{-2} \mathrm{sr}^{-1} \mathrm{~nm}^{-1}$ ). The solar zenith angle is $50^{\circ}$ and the viewing direction is nadir. Zoom windows highlight filled-in Fraunhofer lines in the continuum; the magenta line in the zoom window of the right panel is given an artificial vertical offset to better reveal small filling-in peaks still visible at this spectral resolution. Note that filling-in of Fraunhofer lines inside the $\mathrm{O}_{2} \mathrm{~A}$ band occurs as well. Simulated measurements in the right panel correspond to retrievals in Fig. 4 described in Sect. 4.2. Note that the actual fit window extends from 758 to $770 \mathrm{~nm}$.

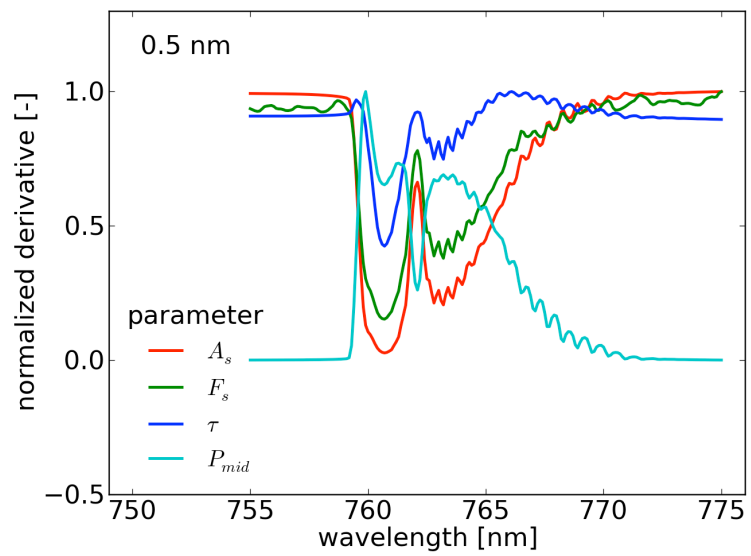

Fig. 2. Derivatives of reflectance with respect to surface albedo $\left(A_{\mathrm{S}}\right)$, fluorescence emission $\left(F_{\mathrm{S}}\right)$, aerosol optical thickness $(\tau)$ and aerosol layer mid pressure $\left(P_{\text {mid }}\right)$ at a spectral resolution of $0.5 \mathrm{~nm}$ and normalized to 1.0 at their respective maximums. Derivatives are for the same atmospheric scenario as in Figs. 1 and 4, which is described in Sect. 4.2, except that the surface albedo and surface emission here are assumed to be independent of wavelength for ease of interpretation. Note that the actual fit window extends from 758 to $770 \mathrm{~nm}$.

the continuum due to the filling-in of Fraunhofer lines. This figure suggests that fluorescence emissions will indeed disturb retrieval of surface albedo and of aerosol parameters through correlations, if substantial fluorescence is present and not taken into account. However, retrieval simulations are needed to investigate whether spectral shapes are still sufficiently different to fit aerosol and fluorescence parameters simultaneously and obtain acceptable precision levels.

In other words, if the objective of retrieval is to estimate aerosol parameters from the $\mathrm{O}_{2} \mathrm{~A}$ band, the question is whether the filling-in of Fraunhofer lines across the $\mathrm{O}_{2} \mathrm{~A}$ band as well as the filling-in of the $\mathrm{O}_{2}$ A band itself provide sufficient independent information to retrieve aerosol and fluorescence parameters simultaneously and avoid biases in retrieved aerosol parameters. If this is not the case, external information on fluorescence emission is needed to minimize its impact on aerosol retrieval. Note that if the objective of retrieval is to estimate fluorescence emissions, it is much more efficient to use filling-in of Fraunhofer lines outside atmospheric absorption bands, because complicated radiative transfer calculations are not needed (Frankenberg et al., 2011a; Joiner et al., 2011, 2012b, 2013; Guanter et al., 2012).

In this paper we therefore take the following approach to answering the question of how well we can retrieve aerosol parameters from the $\mathrm{O}_{2} \mathrm{~A}$ band in the presence of chlorophyll fluorescence. For a number of atmospheric states, observation geometries and instrument properties, we perform a linear error analysis when simultaneously fitting aerosol and fluorescence parameters to investigate errors in retrieved 
parameter values. Next to instrument noise, we also take calibration errors into account. Contributions of model parameter uncertainties (single scattering albedo, temperature profile and surface pressure) are included in reported precision levels by adding these parameters to the state vector with appropriate a priori errors. In the end, the question as to whether or not aerosol and fluorescence parameters can be simultaneously retrieved should of course be understood in terms of meeting scientific user requirements: precision levels reported in this paper may be compared with such requirements to decide whether or not precision levels are indeed acceptable. The focus of this paper is the effect of fluorescence on the retrieval of aerosol parameters. However, we will also report retrieval precision of fluorescence emissions.

The instrument noise model that we use for our simulations assumes that measurement noise is dominated by shot noise. Results are thus particularly relevant for missions carrying grating spectrometers for which the shot noise assumption is reasonable. This includes future satellite instruments such as TROPOMI on the Sentinel-5 Precursor mission, spectrometers on the Sentinel-5 and Sentinel-4 missions, the Orbiting Carbon Observatory-2 instrument (OCO-2: Crisp et al., 2004), and instruments on the Earth Explorer 8 candidate missions Carbon Monitoring Satellite (CarbonSat: Meijer et al., 2012; Bovensmann et al., 2010) and FLuorescence EXplorer (FLEX: Kraft et al., 2012; ESA, 2008). Other satellite instruments include SCIAMACHY and the Global Ozone Monitoring Experiment-2 (GOME-2: Callies et al., 2000).

The paper is structured as follows: Sect. 2 gives a description of the forward model. Section 3 describes the method to calculate retrieval precision in more detail. Section 4 presents results from the simulations. Section 5 provides a discussion of these results.

\section{Forward model}

\subsection{Overview}

The forward model used to calculate reflectance spectra and derivatives is part of a software package developed at the Royal Netherlands Meteorological Institute (KNMI) called DISAMAR. The abbreviation DISAMAR stands for Determining Instrument Specifications and Analyzing Methods for Atmospheric Retrieval. It is a comprehensive tool to support the development at KNMI of Level-2 algorithms for satellite measurements of backscattered solar radiation.

Measured reflectance is defined as

$R\left(\lambda_{i}\right)=\frac{\pi I\left(\lambda_{i}\right)}{\mu_{0} E_{0}\left(\lambda_{i}\right)}$

where $\mu_{o}$ is the cosine of the solar zenith angle $\theta_{o}$, and $I\left(\lambda_{i}\right)$ and $E_{0}\left(\lambda_{i}\right)$ are the radiance and solar irradiance measured in the $i$-th spectral bin, respectively (the $i$-th bin is assigned nominal wavelength $\lambda_{i}$ ). When simulating reflectance spec- tra, measured radiance $I\left(\lambda_{i}\right)$ and irradiance $E_{0}\left(\lambda_{i}\right)$ result after convolving monochromatic (or high-resolution) radiance $I(\lambda)$ and irradiance $E_{0}(\lambda)$ with their respective slit functions. Monochromatic radiance, in turn, is calculated by multiplying monochromatic reflectance from the radiative transfer model by the high-resolution solar irradiance spectrum and adding a fluorescence term. The radiative transfer model also provides derivatives of high-resolution reflectance spectra. These derivatives are appropriately convolved with the radiance slit function to give derivatives of measured reflectance spectra (matrix $\mathbf{K}$, see below).

Hence, key elements of the forward model are a highresolution solar irradiance spectrum, an atmospheric model (including oxygen absorption cross-section data) to describe the atmosphere-surface system, a radiative transfer model to calculate monochromatic reflectance and an instrument model to describe the physics of the instrument. These elements will be discussed in more detail below.

\subsection{High-resolution solar irradiance spectrum}

We use the high-resolution solar reference spectrum by Chance and Kurucz (2010), which has a full width at half maximum (FWHM) of $0.04 \mathrm{~nm}$ and is oversampled by a factor of four. The depth of Fraunhofer lines may thus be slightly underestimated. We only investigate effects of spectral resolution of the observation for FWHMs of $0.1 \mathrm{~nm}$ and larger in order to avoid retrieval artifacts due to the solar spectrum's finite resolution.

\subsection{Atmospheric model}

We choose a simple but generic atmospheric model to describe an atmosphere in which Rayleigh scattering, oxygen absorption, and scattering and absorption by aerosols take place.

The ground surface is modeled as an isotropically reflecting (Lambertian) surface. Since we are interested in the effect of chlorophyll fluorescence, we only consider a vegetated land albedo $A_{\mathrm{s}}$ of 0.20 at $758 \mathrm{~nm}$ (Koelemeijer et al., 2003). In some simulations, the albedo is assumed to be independent of wavelength across the spectral window. In other simulations, the surface albedo slopes linearly upward from 0.20 at $758 \mathrm{~nm}$ to 0.25 at $770 \mathrm{~nm}$ in order to model a more realistic spectral dependence.

Chlorophyll fluorescence is modeled as an isotropic contribution to the upwelling radiance field at the surface in units of $10^{12}$ photons s $\mathrm{cm}^{-1} \mathrm{sr}^{-1} \mathrm{~nm}^{-1}$. The maximum fluorescence emission near the start of the $\mathrm{O}_{2} \mathrm{~A}$ band as retrieved by Guanter et al. (2012) is $1.8 \mathrm{~mW} \mathrm{~m}^{-2} \mathrm{sr}^{-1} \mathrm{~nm}^{-1}$ (monthly $2^{\circ}$ by $2^{\circ}$ average). This value corresponds to $0.7 \times 10^{12}$ photons $\mathrm{s}^{-1} \mathrm{~cm}^{-2} \mathrm{sr}^{-1} \mathrm{~nm}^{-1}$ at the start of the spectral window $(758 \mathrm{~nm})$. The fluorescence emission $F_{S}$ is fully incorporated into the radiative transfer model: upon transmission to the top of atmosphere, the emission may undergo 
not only absorption by oxygen, but also Rayleigh scattering and aerosol extinction. In some simulations, the fluorescence emission (in $10^{12}$ photons $\mathrm{s}^{-1} \mathrm{~cm}^{-2} \mathrm{sr}^{-1} \mathrm{~nm}^{-1}$ ) is assumed to be independent of wavelength across the spectral window. In other simulations, the fluorescence emission slopes linearly downward across the spectral window (such that emission is smaller by a factor of 2 at the end of the window) in order to model a more realistic spectral dependence.

The conventional unit of fluorescence in the literature is $\mathrm{mW} \mathrm{m}{ }^{-2} \mathrm{sr}^{-1} \mathrm{~nm}^{-1}$. Fluorescence emissions in our simulations (in $10^{12}$ photons $\mathrm{s}^{-1} \mathrm{~cm}^{-2} \mathrm{sr}^{-1} \mathrm{~nm}^{-1}$ ) depend on wavelength in that unit. We therefore report simulation results in units of $10^{12}$ photons $\mathrm{s}^{-1} \mathrm{~cm}^{-2} \mathrm{sr}^{-1} \mathrm{~nm}^{-1}$. For comparison with previous studies, we convert results into units of $\mathrm{mW} \mathrm{m}{ }^{-2} \mathrm{sr}^{-1} \mathrm{~nm}^{-1}$ where appropriate, taking $758 \mathrm{~nm}$ as the reference wavelength.

An aerosol layer is modeled as a layer of particles with an associated optical thickness $\tau$ (constant volume extinction coefficient within the layer). Aerosols have a single scattering albedo of 0.95 and a Henyey-Greenstein phase function with an asymmetry parameter of 0.7 , which represents an average aerosol model (cf. Dubovik et al., 2002). Optical thickness, single scattering albedo and phase function are assumed to be independent of wavelength across the spectral window. Optical thicknesses reported in this paper thus hold for wavelengths of the $\mathrm{O}_{2} \mathrm{~A}$ band and are denoted as $\tau(760 \mathrm{~nm})$.

Furthermore, we take a simplified aerosol profile that consists of a single layer with a fixed pressure difference between top and base of $100 \mathrm{hPa}$ - pressure is the independent height variable. Hence a layer with a mid pressure $P_{\text {mid }}$ of $700 \mathrm{hPa}$ is located between 750 and $650 \mathrm{hPa}$.

Finally, we use a mid-latitude summer temperature profile. Rayleigh scattering is specified according to Bodhaine et al. (1999). The surface pressure is $1013 \mathrm{hPa}$. Oxygen is assumed to have a constant volume mixing ratio of $20.95 \%$. In addition to line absorption, we include first-order line mixing and collision-induced absorption by $\mathrm{O}_{2}-\mathrm{O}_{2}$ and $\mathrm{O}_{2}-\mathrm{N}_{2}$ according to the papers by Tran et al. (2006) and Tran and Hartmann (2008). In agreement with Tran and Hartmann (2008), line parameters (three isotopologues) are taken from the Jet Propulsion Laboratory database.

\subsection{Radiative transfer model}

Monochromatic reflectances are calculated with the layerbased orders of scattering method. This is a variant of the doubling-adding method (e.g., De Haan et al., 1987; Hovenier et al., 2004) in which the adding of different layers is replaced by orders of scattering for the atmospheric layers. Multiple scattering is taken into account, but polarization is ignored. Rotational Raman scattering is ignored as well (see Sect. 5). A pseudo-spherical correction is used as in Caudill et al. (1997). The spectral window extends from 758 to $770 \mathrm{~nm}$, which covers almost the entire $\mathrm{O}_{2} \mathrm{~A}$ band. Wavelengths beyond $770 \mathrm{~nm}$ do not contribute additional in- formation content (Siddans et al., 2007). Calculations are done with high accuracy using nine Gaussian points for integration over the polar angle (eighteen streams). Other settings for the radiative transfer calculations are optimized for accuracy as well.

It is essential that derivatives are calculated accurately when assessing whether aerosol and fluorescence parameters can be simultaneously determined from the measurement. Derivatives of monochromatic reflectance with respect to the fit parameters are calculated in a semi-analytical manner using reciprocity (equivalent to the adjoint method; e.g., Landgraf et al., 2001). Such an approach is preferred over numerical techniques (e.g., finite-difference methods), because derivatives can be calculated faster and much more accurately.

\subsection{Instrument model}

The instrument model contains slit functions for the convolution of high-resolution radiance spectra, irradiance spectra and derivatives. In addition, it contains a noise model to associate radiance and irradiance spectra with noise spectra. In some simulations, we also model a calibration error in reflectance spectra. Measurement noise and calibration errors are used to construct the measurement error covariance matrices $\mathbf{S}_{\varepsilon}$. Measurement noise and calibration errors are not added to the simulated reflectance spectra.

We assume that measurement noise can be characterized by shot noise. In that case, the signal-to-noise ratio (SNR) of the radiance $L$ is proportional to the square root of the radiance (in photons):

$\operatorname{SNR}\left(L\left(\lambda_{i}\right)\right)=f\left(\lambda_{i}\right) \cdot \sqrt{L\left(\lambda_{i}\right)}$.

In addition, we assume that the proportionality factor $f\left(\lambda_{i}\right)$ is independent of wavelength. If we know the signal-to-noise ratio for a reference radiance level $L^{\text {ref }}$ at a reference wavelength $\lambda_{i}^{\text {ref }}$, we can calculate the signal-to-noise ratio for any other radiance level at any other wavelength following

$\operatorname{SNR}\left(L\left(\lambda_{i}\right) ; \Delta \lambda\right)=\operatorname{SNR}\left(L^{\mathrm{ref}}\left(\lambda_{i}^{\mathrm{ref}}\right) ; \Delta \lambda^{\mathrm{ref}}\right) \cdot \sqrt{\frac{L\left(\lambda_{i}\right)}{L^{\mathrm{ref}}\left(\lambda_{i}^{\text {ref }}\right)}} \cdot \sqrt{\frac{\Delta \lambda}{\Delta \lambda^{\text {ref }}}} \cdot$

Here, we have also explicitly accounted for the dependence of signal-to-noise ratio on spectral sampling interval $\Delta \lambda$ (spectral bin). Finally, we assume the signal-to-noise ratio of the irradiance to be a factor of ten higher than the signalto-noise ratio of the reference radiance.

The default instrument model for this study consists of anticipated instrument characteristics for TROPOMI (Veefkind et al., 2012). The TROPOMI instrument model will be used in a set of simulations investigating the dependence of retrieval precision on atmospheric parameters. The radiance and irradiance slit functions $S$ at the $\mathrm{O}_{2}$ A band are flattopped functions with a full width at half maximum of 
$0.5 \mathrm{~nm}:$

$$
S\left(\lambda_{i}, \lambda\right)=\text { const } \cdot 2^{-\left(\frac{\lambda_{i}-\lambda}{\text { FWHM/2 }}\right)^{4}}
$$

The constant "const" normalizes the slit function to unit area. The spectral sampling interval is $0.1 \mathrm{~nm}$. The signal-to-noise ratio at $758 \mathrm{~nm}$ (continuum) is 500 for a reference radiance $L^{\text {ref }}(758 \mathrm{~nm})$ of $4.5 \times 10^{12}$ photons $\mathrm{s}^{-1} \mathrm{~cm}^{-2} \mathrm{sr}^{-1} \mathrm{~nm}^{-1}$. The reference radiance spectrum, which is used for specification of the SNR within the Sentinel-5 and Sentinel-5 Precursor projects, corresponds to a dark scene ("tropical dark", meaning a pure molecular atmosphere with a surface albedo of 0.02 , a solar zenith angle of $0^{\circ}$ and a viewing zenith angle of $0^{\circ}$ ). Hence, if clouds or aerosols are present, or if the surface albedo is larger than 0.02, the actual SNR will be (much) larger than 500. Furthermore, we take a multiplicative calibration error to reflectance of $1 \%$, which is the expected radiometric accuracy for the TROPOMI near-infrared bands. Calibration errors for different wavelengths are typically strongly correlated, and we assume a correlation (efolding) length of $100 \mathrm{~nm}$, which is the width of TROPOMI's near-infrared detector.

In subsequent simulations, we investigate the dependence of retrieval precision on spectral resolution and signal-tonoise ratio. When decreasing the FWHM, we keep the spectral sampling ratio constant (i.e., 5) and adjust the spectral sampling interval $(\Delta \lambda)$ accordingly (e.g., a spectral bin of $0.02 \mathrm{~nm}$ at a FWHM of $0.1 \mathrm{~nm}$ ). We also keep the number of photons entering the detector constant. Hence, signal-tonoise ratio will be scaled according to Eq. (3). Signal-tonoise ratios reported in this paper are always reference values that hold for the default TROPOMI spectral sampling interval of $0.1 \mathrm{~nm}$ and the TROPOMI reference radiance at $758 \mathrm{~nm}$ mentioned above.

\section{Error propagation}

For various atmospheric states, observation geometries and instrument properties, we simulate reflectance spectra of the $\mathrm{O}_{2} \mathrm{~A}$ band using the forward model described in Sect. 2. We associate these reflectance spectra with corresponding measurement error covariance matrices. The forward model also provides derivatives of reflectance spectra with respect to the various fit parameters (e.g., aerosol and fluorescence parameters). We then calculate 1- $\sigma$ errors in fit parameters by propagating measurement errors and a priori errors according to the optimal estimation formalism (Rodgers, 2000).

In symbols: let us assume that the forward model $\boldsymbol{F}$ can be linearized for the purposes of an error analysis. We write

$\boldsymbol{R} \approx \boldsymbol{F}(\hat{\boldsymbol{x}})+\mathbf{K}(\boldsymbol{x}-\hat{\boldsymbol{x}})$,

where $\boldsymbol{R}$ is the vector of measured reflectances, $\boldsymbol{x}$ is the state vector containing the fit parameters and $\mathbf{K}=\partial \boldsymbol{F}(\boldsymbol{x}) / \partial \boldsymbol{x}$ is the Jacobian matrix (evaluated here at $\hat{\boldsymbol{x}}$ ). The $i$-th element of $\boldsymbol{R}$ is the reflectance at wavelength $\lambda_{i}$. The reflectance is subject to measurement error, which is described by the measurement error covariance matrix $\mathbf{S}_{\varepsilon}$ :

$\left(\mathbf{S}_{\varepsilon}\right)_{i j}=\left\{\begin{array}{cl}\sigma_{\varepsilon}^{2}\left(R_{i}\right)+\sigma_{\text {calib }}^{2}\left(R_{i}\right) & i=j \\ \sigma_{\text {calib }}\left(R_{i}\right) \cdot \sigma_{\text {calib }}\left(R_{j}\right) \cdot \exp \left(-\frac{\left|\lambda_{i}-\lambda_{j}\right|}{\Delta l}\right) & i \neq j\end{array}\right.$,

where $\sigma_{\varepsilon}^{2}\left(R_{i}\right)$ is the variance of the noise error in $R_{i}$, $\sigma_{\text {calib }}^{2}\left(R_{i}\right)$ the variance of the calibration error in $R_{i}$ and $\Delta l$ is the calibration error's correlation length. The noise error and calibration error are calculated according to the instrument model described in Sect. 2.5. The covariance matrix $\hat{\mathbf{S}}$ describing the error in retrieved parameters $\hat{\boldsymbol{x}}$ is then given by:

$\hat{\mathbf{S}}=\left(\mathbf{K}^{T} \mathbf{S}_{\varepsilon}^{-1} \mathbf{K}+\mathbf{S}_{\mathrm{a}}^{-1}\right)^{-1}$.

in which $\mathbf{S}_{\mathrm{a}}$ is the covariance matrix describing knowledge of the fit parameters prior to the measurement. We assume that the a priori covariance matrix is diagonal, i.e., a priori errors are uncorrelated.

A column of $\mathbf{K}$ corresponds to the derivative of reflectance with respect to a particular fit parameter as a function of wavelength (after appropriate convolution with the slit function). If columns of $\mathbf{K}$ become strongly linearly dependent, the matrix $\mathbf{K}^{T} \mathbf{S}_{\varepsilon}^{-1} \mathbf{K}$ will be nearly singular and the error in some retrieved parameters (diagonal elements of $\hat{\mathbf{S}}$ ) can become large (or rather, it becomes limited by the a priori error). Note that if columns of $\mathbf{K}$ are nearly linearly dependent, the solution $\hat{\boldsymbol{x}}$ will typically also be more sensitive to systematic errors such as numerical inaccuracies or model parameter errors.

Here, we investigate the effect of model parameter errors by including a number of the main model parameters in the state vector and assigning them appropriate a priori errors (cf. retrieval of the "full state vector"; Rodgers, 2000, Sect. 4.1.2). The a posteriori error covariance matrix then provides the sum of the covariances of retrieval errors due to measurement noise, smoothing errors and model parameter errors. The state vector thus contains the retrieval quantities of interest (aerosol pressure, aerosol optical thickness), other retrieval quantities for which the measurement may contain information (e.g., fluorescence emission), and true model parameters for which the measurement probably does not contain any information (e.g., aerosol single scattering albedo). In the latter case, the posterior covariance is equal to the prior covariance, which affects precision of retrieval quantities through correlations.

We calculate retrieval precision for a full state vector and for a reduced state vector. State vector elements and a priori errors are given in Table 1 (a priori values are equal to true values). The main fit parameters are mid pressure of the aerosol layer $\left(P_{\text {mid }}\right)$, aerosol optical thickness $(\tau(760 \mathrm{~nm}))$ and surface albedo $\left(A_{\mathrm{s}}\right)$. These parameters have large a priori errors. Note that retrieved optical thickness should be interpreted in terms of the aerosol model assumed in retrieval. 
Table 1. State vector elements and a priori errors used for calculating retrieval precision. For retrieval of the reduced state vector, the measurement error covariance matrix comprises noise errors, and the surface albedo and fluorescence emissions are assumed constant across the fit window. For retrieval of the full state vector, the measurement error covariance matrix comprises noise and calibration errors, and the wavelength dependence of the surface albedo and fluorescence emissions in retrieval is described by a second-order polynomial (three wavelength nodes).

\begin{tabular}{|c|c|c|}
\hline \multirow{2}{*}{ State vector element } & \multicolumn{2}{|c|}{ A priori error } \\
\hline & Reduced state vector & Full state vector \\
\hline Aerosol mid pressure $\left(P_{\text {mid }}\right)$ & $500 \mathrm{hPa}$ & $500 \mathrm{hPa}$ \\
\hline Aerosol optical thickness $(\tau(760 \mathrm{~nm}))$ & 2.0 & 2.0 \\
\hline Surface albedo $\left(A_{\mathrm{S}}\right)$ & 0.2 & \\
\hline Surface albedo $\left(A_{\mathrm{s}}^{758}, A_{\mathrm{s}}^{764}, A_{\mathrm{s}}^{770}\right)$ & & 0.2 \\
\hline Fluorescence emission $\left(F_{\mathrm{S}}\right)$ & $\begin{array}{r}1.0 \times 10^{12} \\
\text { photons s}{ }^{-1} \mathrm{~cm}^{-2} \\
\mathrm{sr}^{-1} \mathrm{~nm}^{-1}\end{array}$ & \\
\hline Fluorescence emission $\left(F_{\mathrm{s}}^{758}, F_{\mathrm{s}}^{764}, F_{\mathrm{s}}^{770}\right)$ & & $\begin{array}{r}1.0 \times 10^{12} \\
\text { photons s}{ }^{-1} \mathrm{~cm}^{-2} \\
\mathrm{sr}^{-1} \mathrm{~nm}^{-1}\end{array}$ \\
\hline Single scattering albedo $(\omega)$ & & 0.05 \\
\hline Surface pressure $\left(p_{\mathrm{S}}\right)$ & & $3 \mathrm{hPa}$ \\
\hline Temperature profile $\left(T\left(\mathrm{p}_{i}\right)\right)$ & & $2 \mathrm{~K}$ (correlation length of $6 \mathrm{~km}$ ) \\
\hline
\end{tabular}

Surface albedo and surface emission $\left(F_{\mathrm{S}}\right)$ are assumed constant across the fit window when retrieving the reduced state vector; surface albedo and surface emission are described by a second-order polynomial when retrieving the full state vector (three wavelength nodes). Although a linear wavelength dependence seems sufficient to describe the spectral behavior of realistic surface albedos (Koelemeijer et al., 2003) and realistic surface emissions (Amoros-Lopez et al., 2008; Guanter et al., 2010) across the $\mathrm{O}_{2} \mathrm{~A}$ band, we use a secondorder polynomial for the wavelength dependence in the forward model for retrieval to allow the retrieval to account for any residual higher-order spectral variations. Furthermore, the full state vector contains the single scattering albedo $(\omega)$, surface pressure $\left(P_{\mathrm{S}}\right)$ and the temperature profile $\left(T\left(p_{i}\right)\right)$. Finally, the measurement error covariance matrix comprises noise errors when retrieving the reduced state vector, and it comprises noise and calibration errors when retrieving the full state vector.

We take an a priori error of 0.05 for the single scattering albedo. Thus, for a single scattering albedo of 0.95 , the $3-\sigma$ range covers 0.80 to 1.0 , which is about the range of typical single scattering albedos. We assume that the fluorescence emission is known with an a priori error of $1.0 \times 10^{12}$ photons s${ }^{-1} \mathrm{~cm}^{-2} \mathrm{sr}^{-1} \mathrm{~nm}^{-1}$; the $3-\sigma$ range then also covers the range of realistic emissions (Guanter et al., 2012). Furthermore, we assume that the surface pressure is known with an a priori error of $3 \mathrm{hPa}$, which is in agreement with root-mean-square differences between ground station observations and spatiotemporally interpolated $1^{\circ}$ by $1^{\circ}$ ECMWF (European Centre for Medium-range Weather
Forecasts) fields as found by Salstein et al. (2008). Finally, we take an a priori error for the temperature profile of $2 \mathrm{~K}$ at every pressure level with a correlation length of $6 \mathrm{~km}$. Other important forward model uncertainties that are not considered include the phase function and the presence of multiple aerosol/cloud layers (a single scattering layer is assumed in the retrieval).

Note that we assume that a linear error analysis can indeed be performed. In other words, we assume that for a specific atmospheric state the forward model is approximately linear within the measurement and a priori error. If the model is non-linear, convergence may be problematic or multiple minima in the cost function may exist. Investigating the effect of non-linearities on convergence and stability of retrieval is beyond the scope of this paper.

\section{Results}

\subsection{Dependence on atmospheric parameters}

In a first set of simulations, we investigate the dependence of retrieval precision on atmospheric parameters and solar and viewing zenith angles. We use the TROPOMI instrument model described in the previous section. Figure 3 shows the dependence of precision of aerosol mid pressure (first row), aerosol optical thickness (second row), surface albedo (third row), and fluorescence emission (fourth row) on aerosol optical thickness for three values of the mid pressure of the aerosol layer. The left column corresponds to retrieval of the reduced state vector excluding calibration errors; the 

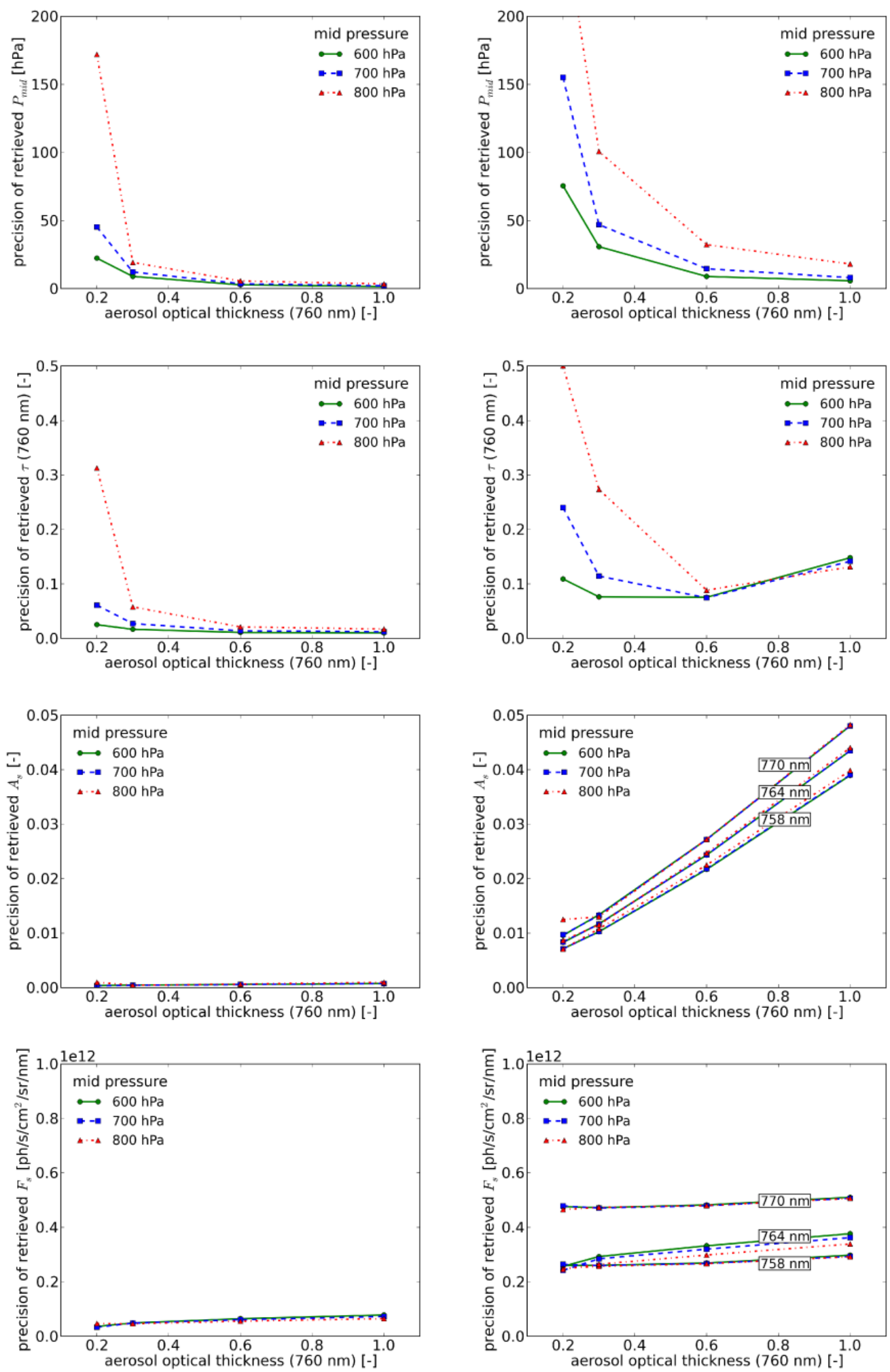

Fig. 3. Precision of the main fit parameters as a function of optical thickness for three values of the mid pressure of the aerosol layer. Left column: retrieval of reduced state vector; right column: retrieval of full state vector (for an explanation, see the text and Table 1). First row: mid pressure $\left(P_{\text {mid }}\right)$; second row: aerosol optical thickness $(\tau)$; third row: surface albedo $\left(A_{\mathrm{S}}\right)$; fourth row: fluorescence emission $\left(F_{\mathrm{S}}\right)$. Aerosols have a single scattering albedo of 0.95 and a Henyey-Greenstein phase function with an asymmetry parameter of 0.7 ; the aerosol layer has a pressure thickness of $100 \mathrm{hPa}$; the ground surface has an albedo of 0.20 at $758 \mathrm{~nm}$ and exhibits fluorescence emissions. In case of the reduced state vector, the surface albedo and fluorescence emission are constant across the fit window. In case of the full state vector, the surface albedo slopes linearly upward from 0.20 at $758 \mathrm{~nm}$ to 0.25 at $770 \mathrm{~nm}$ and the fluorescence emission slopes linearly downward such that emission is smaller by a factor of 2 at the end of the fit window. Note, however, that the full state vector contains the surface albedo and fluorescence emission at wavelength nodes 758,764 and $770 \mathrm{~nm}$ : in retrieval, these parameters are in principle allowed to depend quadratically on wavelength. Absolute errors were the same across the range of fluorescence emissions investigated (see text). The solar zenith angle is $50^{\circ}$ and the viewing direction is nadir. Results hold for the TROPOMI instrument model (FWHM of $0.5 \mathrm{~nm}$ ). Note that precision values for $F_{\mathrm{S}}$ are scaled with a factor $1 \times 10^{12}$. 

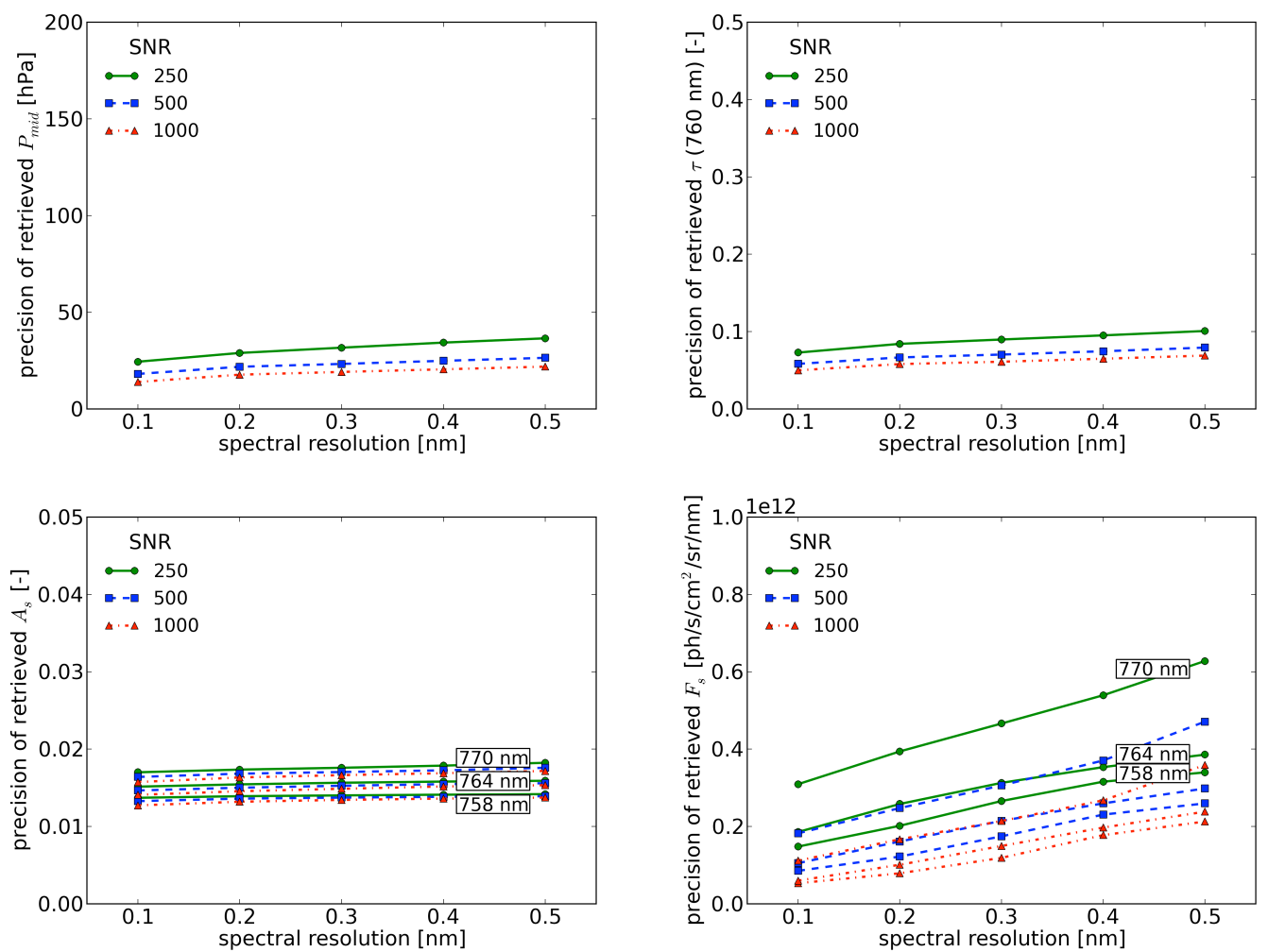

Fig. 4. Precision of the main fit parameters as a function of spectral resolution for three values of the signal-to-noise ratio and for retrieval of the full state vector. Top left: mid pressure $\left(P_{\mathrm{mid}}\right)$; top right: aerosol optical thickness $(\tau)$; bottom left: surface albedo $\left(A_{\mathrm{S}}\right)$ at three wavelength nodes; bottom right: fluorescence emission $\left(F_{\mathrm{S}}\right)$ at three wavelength nodes. Results are for the following atmospheric scenario: aerosol layer at $700 \mathrm{hPa}$ with optical thickness of 0.4 , default aerosol model, surface albedo at $758 \mathrm{~nm}$ of 0.20 , and a fluorescence emission at $758 \mathrm{~nm}$ of $0.46 \times 10^{12}$ photons s $\mathrm{cm}^{-1} \mathrm{sr}^{-1} \mathrm{~nm}^{-1}$ (or $1.2 \mathrm{~mW} \mathrm{~m}^{-2} \mathrm{sr}^{-1} \mathrm{~nm}^{-1}$ ). The solar zenith angle is $50^{\circ}$ and the viewing direction is nadir. The reference signal-to-noise ratios hold for the TROPOMI reference radiance at $758 \mathrm{~nm}$ and spectral sampling interval of $0.1 \mathrm{~nm}$. When varying spectral resolution, signal-to-noise ratios are scaled with the square root of the spectral sampling interval (the amount of light entering detector is constant). For details, see Sect. 2.5. Note that precision values for $F_{\mathrm{S}}$ are scaled with factor $1 \times 10^{12}$.

right column corresponds to retrieval of the full state vector including calibration errors and uncertainties in additional model parameters. For easy comparison, scales along the $y$ axes are the same. Results are presented for a solar zenith angle of $50^{\circ}$ and nadir viewing direction. We will summarize the main findings.

Dependence on fluorescence emission. Fluorescence emissions ranged between a minimum of 0.0 and a maximum of $0.7 \times 10^{12}$ photons s $\mathrm{s}^{-1} \mathrm{~cm}^{-1} \mathrm{sr}^{-1} \mathrm{~nm}^{-1}$ at $758 \mathrm{~nm}$ (or $1.8 \mathrm{~mW} \mathrm{~m}^{-2} \mathrm{sr}^{-1} \mathrm{~nm}^{-1}$ ). Absolute errors in the main fit parameters are the same when varying fluorescence emissions between zero emission and maximum emission and keeping the a priori error the same. The results presented in Fig. 3 therefore hold for fluorescence emissions in this range. Relative errors in retrieved fluorescence emission of course decrease with increasing emissions.

Dependence on aerosol optical thickness. The precision of retrieved aerosol mid pressure and optical thickness generally improves with increasing $\tau$ (stronger aerosol signal). One can see that the precision of retrieved aerosol optical thickness is slightly worse for an optical thickness at $760 \mathrm{~nm}$ of 1.0 compared to an optical thickness of 0.6 when the full state vector is retrieved. This is presumably due to the uncertainty in the single scattering albedo. Precision of retrieved surface albedo and fluorescence emission generally deteriorates with increasing $\tau$ (shielding of the surface below the aerosol layer).

Dependence on mid pressure. The precision of aerosol parameters generally improves with decreasing pressure (increasing altitude). For larger pressure differences between aerosol layer and ground surface, it is easier to distinguish aerosol contributions from surface contributions.

Dependence on solar zenith angle. We test retrieval precision for solar zenith angles of 0,50 and $75^{\circ}$ (not shown). Precision of aerosol parameters tends to improve with increasing solar zenith angle. If the solar zenith angle increases, a unit area of surface receives less light (weaker aerosol signal) but path lengths through the aerosol layer are longer (stronger aerosol signal). Apparently, the latter effect dominates. As for the dependence of precision of retrieved fluorescence 

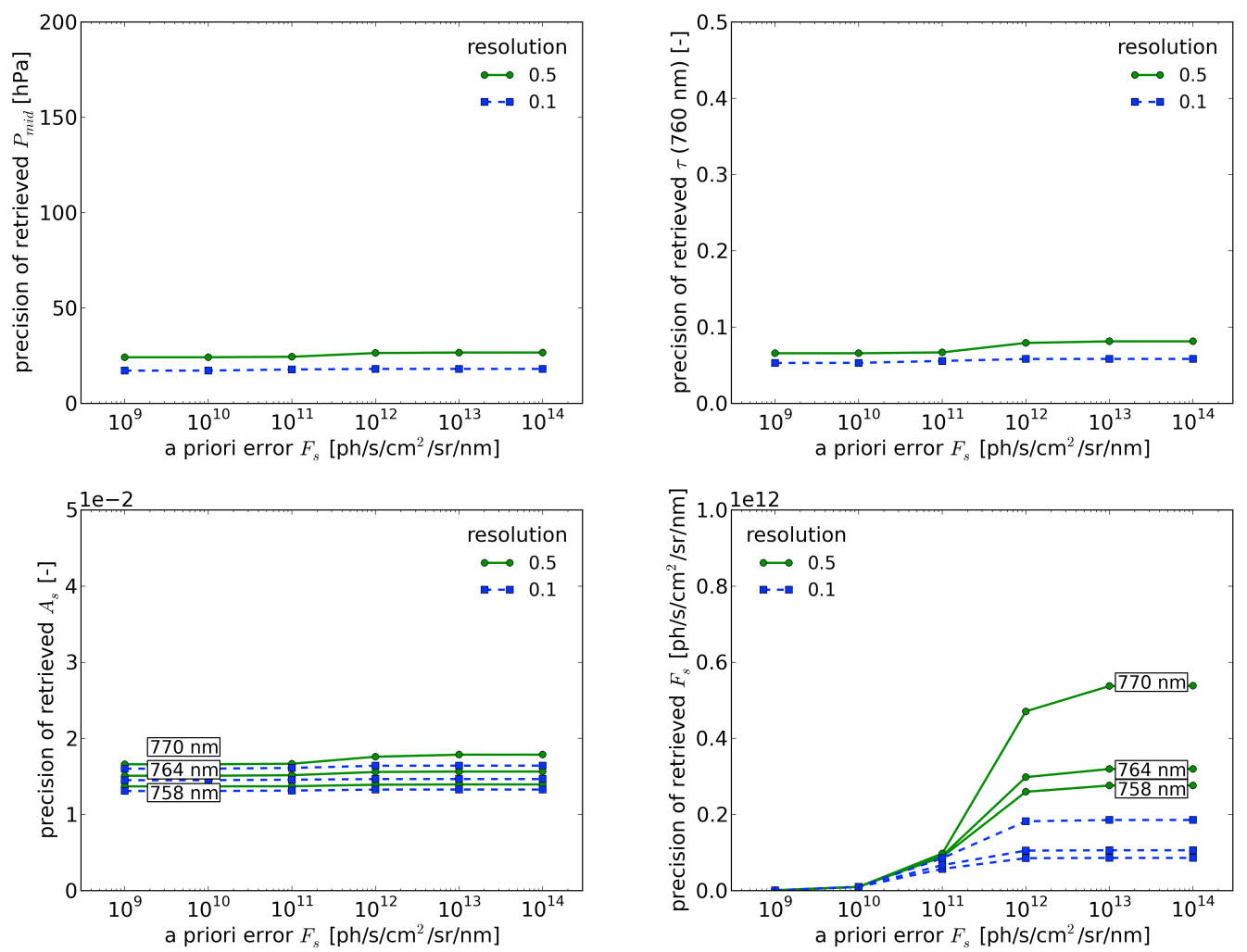

Fig. 5. Precision of the main fit parameters as a function of the a priori error in the fluorescence emission for two spectral resolutions and for retrieval of the full state vector. Top left: mid pressure $\left(P_{\text {mid }}\right)$; top right: aerosol optical thickness $(\tau)$; bottom left: surface albedo $\left(A_{\mathrm{S}}\right)$ at three wavelength nodes; bottom right: fluorescence emission $\left(F_{\mathrm{S}}\right)$ at three wavelength nodes. Results correspond to the same atmospheric scenario and observation geometry as in Fig. 4 . The reference signal-to-noise ratio is 500 . Note that precision values for $F_{\mathrm{S}}$ are scaled by a factor of $1 \times 10^{12}$.

emissions on solar zenith angle, we cannot make any statements with our forward model. We model fluorescence emission at canopy level as independent of solar zenith angle. However, the broadband downwelling flux of photosynthetically active radiation depends on solar zenith angle and hence so must the fluorescence emission.

Dependence on viewing zenith angle. We test retrieval precision for viewing zenith angles of 0,50 and $70^{\circ}$ (not shown). Precision of aerosol parameters tends to improve with increasing viewing zenith angle (longer path lengths through aerosol layer, hence stronger aerosol signal). Precision of retrieved fluorescence emission typically deteriorates with increasing viewing zenith angle (longer path lengths through aerosol layer, more extinction of fluorescence emission, hence weaker fluorescence signal).

Reduced state vector and full state vector. Precision levels for the full state vector are assumed to represent realistic precision levels and they may be compared against scientific user requirements. We see that errors are considerably larger for retrieval of the full state vector compared to the reduced state vector.

\subsection{Dependence on instrument properties}

In a second set of simulations we investigate the dependence of retrieval precision on spectral resolution and signal-tonoise ratio for retrieval of the full state vector. We assume an atmospheric scenario of an aerosol layer with optical thickness at $760 \mathrm{~nm}$ of 0.4 between 750 and $650 \mathrm{hPa}$, vegetated land with an albedo of 0.20 at $758 \mathrm{~nm}$ and a fluorescence emission of $0.46 \times 10^{12}$ photons s${ }^{-1} \mathrm{~cm}^{-2} \mathrm{sr}^{-1} \mathrm{~nm}^{-1}$ at $758 \mathrm{~nm}$ (or $1.2 \mathrm{~mW} \mathrm{~m}^{-2} \mathrm{sr}^{-1} \mathrm{~nm}^{-1}$ ). The solar zenith angle is $50^{\circ}$ and the viewing direction is nadir. Recall that reported signal-to-noise ratios are reference values that hold for a spectral sampling interval of $0.1 \mathrm{~nm}$ and the TROPOMI reference radiance at $758 \mathrm{~nm}$. The spectral resolution (FWHM) is varied while keeping the spectral sampling ratio constant (i.e., 5). Signal-to-noise ratios are scaled with the square root of the spectral sampling interval (amount of light entering detector is constant). 
Table 2. Benchmark numbers for comparing the precision of retrieved mid pressure, aerosol optical thickness and fluorescence emission as found in this study.

\begin{tabular}{|c|c|c|c|}
\hline Param. & Benchmark & Description & Reference \\
\hline$P_{\text {mid }}$ & $100 \mathrm{hPa}(50 \mathrm{hPa})$ & $\begin{array}{l}\text { TROPOMI threshold (target) requirement on pre- } \\
\text { cision of retrieved Aerosol Layer Height }\end{array}$ & Veefkind et al. (2012) \\
\hline$\tau^{\mathrm{a}}$ & $\pm(0.05+15 \%)^{b}$ & $\begin{array}{l}\text { Large-scale global validation of MODIS aerosol } \\
\text { retrievals over "dark" land (e.g., vegetation) with } \\
\text { AERONET sunphotometer measurements; error } \\
\text { envelope containing two-thirds of all collocations }\end{array}$ & Levy et al. (2010) \\
\hline$F_{\mathrm{S}}$ & $\begin{array}{l}0.04 \times 10^{12}- \\
0.15 \times 10^{12} \text { photons s} \\
\mathrm{cm}^{-2} \mathrm{sr}^{-1} \mathrm{~nm}^{-1 \mathrm{c}}\end{array}$ & $\begin{array}{l}\text { Precision of monthly } 2^{\circ} \text { by } 2^{-1} \text { average } F_{\mathrm{S}} \text { values } \\
\text { at } 755 \mathrm{~nm} \text { retrieved from GOSAT observations; er- } \\
\text { ror estimate includes only measurement noise }\end{array}$ & Guanter et al. (2012) \\
\hline
\end{tabular}

Figure 4 shows the dependence of retrieval precision on resolution for three values of the signal-to-noise ratio. Precision of all four parameters varies almost linearly with spectral resolution. However, the improvement of precision when going to finer resolutions is modest, except for the fluorescence emission at high signal-to-noise ratio.

\subsection{Dependence on a priori error in fluorescence emission}

In a third set of simulations, we investigate the dependence of retrieval precision on the a priori error in the fluorescence emission. We assume the same atmospheric scenario as in Sect. 4.2. Note that, given the range of typical fluorescence emissions, an a priori error of $1.0 \times 10^{12}$ photons $\mathrm{s}^{-1} \mathrm{~cm}^{-2} \mathrm{sr}^{-1} \mathrm{~nm}^{-1}$ essentially corresponds to an unconstrained retrieval (i.e., no a priori knowledge). Interestingly, if the a priori error is decreased below this value, precision of retrieved mid pressure, aerosol optical thickness and surface albedo hardly improve in the range tested. We remark that for low optical thicknesses ( $\tau$ at $760 \mathrm{~nm}$ of, say, 0.2 ) a modest improvement in precision is found (not shown). On the other hand, precision of retrieved fluorescence emission improves if the a priori error is decreased below $1.0 \times 10^{12}$ photons $\mathrm{s}^{-1} \mathrm{~cm}^{-2} \mathrm{sr}^{-1} \mathrm{~nm}^{-1}$. This makes sense, as the a priori error starts dominating the a posteriori error. For example, for an a priori error of $0.1 \times 10^{12}$ photons s $\mathrm{s}^{-1} \mathrm{~cm}^{-2} \mathrm{sr}^{-1} \mathrm{~nm}^{-1}$, precision of retrieved fluorescence is approximately $0.09 \times 10^{12}$ photons $\mathrm{s}^{-1} \mathrm{~cm}^{-2} \mathrm{sr}^{-1} \mathrm{~nm}^{-1}$.

\section{Discussion}

In this study, we have investigated the precision of retrieved parameters for a generic aerosol retrieval algorithm over vegetated land using the $\mathrm{O}_{2} \mathrm{~A}$ band. We have described retrieval precision for various atmospheric states, observation geometries and instrument properties in a number of retrieval sim- ulations. Chlorophyll fluorescence is taken into account in the forward model. Fluorescence emissions are modeled as isotropic contributions to the upwelling radiance field at the surface and they are retrieved along with aerosol parameters. The set of fit parameters comprises the mid pressure of the aerosol layer, aerosol optical thickness, fluorescence emission and surface albedo. An estimate of errors due to model parameter errors (single scattering albedo, temperature profile and surface pressure) is included in the reported precision levels by adding these parameters to the state vector with appropriate a priori errors. Precision is calculated by propagating measurement errors and a priori errors (including model parameter errors) using the forward model's derivatives.

Forward model uncertainties that are not considered in the reported error analysis include the aerosol's phase function and the presence of more than one scattering layer. The reason we have not considered the phase function is that computation of derivatives with respect to the phase function is currently not implemented, as DISAMAR was developed for single-viewing (nadir) instruments. Retrieved optical thickness will thus be an effective quantity that should be interpreted in terms of the phase function assumed in retrieval. Furthermore, we have assumed the existence of a single layer with a fixed pressure difference between top and base in retrieval, because the $\mathrm{O}_{2}$ A band contains limited aerosol profile information (Siddans et al., 2007; Corradini and Cervino, 2006; cf. Daniel et al., 2003). If the assumed pressure thickness differs from the true one or if more than one scattering layer is present, retrieved aerosol mid pressure will be an effective scattering height parameter (cf. Joiner et al., 2012a). Retrieval simulations have shown that biases in retrieved aerosol parameters do not change significantly if the a priori error in the fluorescence emission is reduced as in Fig. 5 (Sect. 4.3).

Whether errors in retrieved parameters are acceptable depends on scientific user requirements. We have reported retrieval errors so that the reader can evaluate their magnitudes. 
Table 3. Instrument specifications of the $\mathrm{O}_{2}$ A band channel for a number of space-borne grating spectrometers that will be operational in the coming years. Numbers printed italic can be used to interpret Fig. 4.

\begin{tabular}{|c|c|c|c|c|c|c|}
\hline Instrument & FWHM & $\Delta \lambda$ & SNR & $L_{\mathrm{ref}}(758 \mathrm{~nm})$ & Reference & SNR-ref. ${ }^{a}$ \\
\hline TROPOMI $^{\mathrm{b}}$ & $0.5 \mathrm{~nm}$ & $0.1 \mathrm{~nm}$ & 500 & $4.5 \times 10^{12}$ photons $\mathrm{s}^{-1} \mathrm{~cm}^{-2} \mathrm{sr}^{-1} \mathrm{~nm}^{-1}$ & Veefkind et al. (2012) & 500 \\
\hline Sentinel-5 & $0.4 \mathrm{~nm}^{\mathrm{c}}$ & $0.13 \mathrm{~nm}$ & 500 & $4.5 \times 10^{12}$ photons s $\mathrm{s}^{-1} \mathrm{~cm}^{-2} \mathrm{sr}^{-1} \mathrm{~nm}^{-1}$ & ESA (2012) & 570 \\
\hline Sentinel-4 & $0.12 \mathrm{~nm}^{\mathrm{d}}$ & $0.04 \mathrm{~nm}$ & 566 & $1.3 \times 10^{13}$ photons s $\mathrm{s}^{-1} \mathrm{~cm}^{-2} \mathrm{sr}^{-1} \mathrm{~nm}^{-1}$ & ESA (2012) & 526 \\
\hline $\mathrm{OCO}-2^{\mathrm{e}}$ & $0.042 \mathrm{~nm}$ & $0.014 \mathrm{~nm}$ & 814 & $3.5 \times 10^{13}$ photons s $\mathrm{s}^{-1} \mathrm{~cm}^{-2} \mathrm{sr}^{-1} \mathrm{~nm}^{-1}$ & Boesch et al. (2011) & 780 \\
\hline CarbonSat & $0.045 \mathrm{~nm}$ & $0.015 \mathrm{~nm}$ & 340 & $2.0 \times 10^{13}$ photons s $\mathrm{sm}^{-1} \mathrm{sr}^{-1} \mathrm{~nm}^{-1}$ & Bovensmann et al. (2010) & 416 \\
\hline CarbonSat $^{\mathrm{f}}$ & $0.1 \mathrm{~nm}$ & $0.033 \mathrm{~nm}$ & 507 & $2.0 \times 10^{13}$ photons s $\mathrm{s}^{-1} \mathrm{~cm}^{-2} \mathrm{sr}^{-1} \mathrm{~nm}^{-1}$ & $\begin{array}{l}\text { Meijer et al. (2012) } \\
\text { and Bovensmann et al. (2010) }\end{array}$ & 620 \\
\hline
\end{tabular}

a: Reference SNR under the assumption of shot noise: holds for $\Delta \lambda$ of $0.1 \mathrm{~nm}$ and TROPOMI reference radiance at $758 \mathrm{~nm} ;{ }^{\mathrm{b}}:$ Sentinel-5 Precursor; ${ }^{\mathrm{c}}:$ threshold value; ${ }^{\mathrm{d}}$ : goal value; e: Note that OCO-2 measures light in only one polarization direction, which we ignore in the computation of the reference signal-to-noise ratio. ${ }^{f}$ : Spectral resolution and sampling ratio are taken from Meijer et al. (2012); signal-to-noise ratio and corresponding radiance are taken from Bovensmann et al. (2010) and scaled to the sampling interval of 0.033 nm assuming shot noise.

Errors in retrieved mid pressure, aerosol optical thickness and fluorescence emission may be put into perspective by comparing them against the benchmark numbers provided in Table 2. If we compare these numbers to retrieval precision for the first set of simulations (TROPOMI instrument model), we can make the following observations. For most cases considered, precision of retrieved pressure is below the TROPOMI threshold requirement of $100 \mathrm{hPa}$ for optical thicknesses (at $760 \mathrm{~nm}$ ) of 0.5 or higher. Precision of retrieved $\tau$ is typically between 0.1 and 0.2 , which is in approximately the same range as the total uncertainty in MODIS optical thickness (at $550 \mathrm{~nm}$ ) as found in the large-scale validation study by Levy et al. (2010), especially for larger optical thicknesses. Finally, the precision of retrieved fluorescence emission at $758 \mathrm{~nm}$ is larger than the precision reported by Guanter et al. (2012) by a factor of 3 to 7 . The error estimates provided by Guanter et al. (2012) include only measurement noise. For viewing zenith angles approaching $70^{\circ}$, however, precision may increase up to $0.8 \times 10^{12}$ photons $\mathrm{s}^{-1} \mathrm{~cm}^{-2} \mathrm{sr}^{-1} \mathrm{~nm}^{-1}$ (not shown), which is quite close to the a priori error.

We have also investigated the dependence of retrieval precision on the a priori error in the fluorescence emission. As the baseline a priori uncertainty we have assumed a 1- $\sigma$ error of $1.0 \times 10^{12}$ photons $\mathrm{s}^{-1} \mathrm{~cm}^{-2} \mathrm{sr}^{-1} \mathrm{~nm}^{-1}$ covering the range of realistic fluorescence emissions at the $\mathrm{O}_{2} \mathrm{~A}$ band. For the case considered, we have found that precision of retrieved aerosol parameters hardly improves if the a priori error is decreased below this value. A fluorescence emission constraint for aerosol retrieval from the $\mathrm{O}_{2} \mathrm{~A}$ band may, for example, be provided in a pre-retrieval step based on a fast fluorescence retrieval using Fraunhofer lines in the continuum. But note that an a priori fluorescence emission from such a pre-retrieval step also has an error, which is supposedly in the range of a priori errors of Fig. 5 (e.g., Buchwitz et al., 2013). The results therefore indicate that if the objective of the $\mathrm{O}_{2}$ A band retrieval is the retrieval of aerosol parameters, precision will hardly benefit from such a pre- retrieval step. Providing a better a priori value in the sense of a starting value for the fit might still help to improve the convergence rate or convergence to the global $\chi^{2}$-minimum in case of a strongly non-linear forward model. This needs to be further investigated.

In Sect. 4, we have described the dependence of retrieval precision on optical thickness, aerosol layer pressure, fluorescence emission, and solar and viewing zenith angles. We remark that exceptions to the overall trends exist. We have noticed in our work on the $\mathrm{O}_{2} \mathrm{~A}$ band that retrieval precision can significantly deteriorate for very specific combinations of aerosol pressure, optical thickness, aerosol properties (phase function and single scattering albedo), surface albedo and observation geometry. These singular cases often occur for optically thin layers over land and may be related (but not limited) to situations of a so-called critical surface albedo (e.g., Seidel and Popp, 2012). This illustrates the importance of a proper error analysis: by calculating derivatives we know whether the system is becoming singular for a specific retrieved state. At this point, it is important to note that these near-singular inversions are characteristic of aerosol retrieval in general and not so much specific for aerosol retrieval over fluorescing vegetated areas.

Finally, the dependence of retrieval precision on spectral resolution and signal-to-noise ratio has been investigated. Table 3 provides instrument specifications for a number of satellite grating spectrometers that will be operational in the coming years. We have also calculated the respective reference signal-to-noise ratios (indicated in italic) that hold for the TROPOMI spectral sampling interval and TROPOMI reference radiance (as in Fig. 4). Prospective retrieval precision for the Sentinel-4/5 instruments, OCO-2 and CarbonSat can be directly evaluated in Fig. 4 using values for the spectral resolution and reference SNR from Table 3. Note that all instruments mentioned in Table 3 are oversampled.

In conclusion, the error analysis indicates that precision of retrieved aerosol parameters is acceptable when aerosol and fluorescence parameters are retrieved simultaneously. In 
addition, the analysis of the dependence on the a priori error in the fluorescence emission indicates that precision of retrieved aerosol parameters hardly improves if external information on fluorescence is available. Thus, we have no indications at this point that aerosol parameters cannot be retrieved from the $\mathrm{O}_{2}$ A band in the presence of chlorophyll fluorescence: if fluorescence is present, fluorescence emissions should and can be included in the state vector to avoid biases in retrieved aerosol parameters. This agrees with Frankenberg et al. (2012) who showed that biases in retrieved $\mathrm{CO}_{2}$ volume mixing ratios and aerosol parameters from the ACOS (Atmospheric Carbon Observations from Space) $\mathrm{CO}_{2}$ retrieval algorithm (O'Dell et al., 2012) decrease if fluorescence is included in the fit (Figs. 5 and 8 in Frankenberg et al., 2012).

Rotational Raman scattering has not been taken into account in this study. There are indications that for typical observation geometries and significant fluorescence emissions (larger than approximately $0.5 \mathrm{~mW} \mathrm{~m}^{-2} \mathrm{sr}^{-1} \mathrm{~nm}^{-1}$ ) the contribution to the top-of-atmosphere radiance due to Rotational Raman scattering is smaller than the contribution due to fluorescence (Vasilkov et al., 2013; Sioris et al., 2003). At first glance, spectral shapes of the two filling-in effects seem comparable (Vasilkov et al., 2013) but there are slight differences; after all, the origins of the respective signals are different. Rotational Raman scattering is well known and can, at least in principle, be included in the radiative transfer calculations. In that case, rotational Raman scattering does not need to be fitted and fluorescence emissions can still be retrieved. The precise effect of disregarding rotational Raman scattering on the retrieval of aerosol from the $\mathrm{O}_{2} \mathrm{~A}$ band in the presence of fluorescence remains to be investigated.

The computational effort for calculating an operational $\mathrm{O}_{2}$ A band aerosol retrieval algorithm is substantial. The most time-consuming step is the radiative transfer modeling: line-by-line calculations are necessary as oxygen is a strong line absorber. Substantial reduction in computation time can be achieved by using variants of $k$-distribution methods (e.g., Hasekamp and Butz, 2008). Errors in radiances can be limited, but errors in derivatives may still be substantial. The effect of these approximations on aerosol retrieval also remains to be investigated.

In our analysis, we have assumed that the retrieval solution $\hat{\boldsymbol{x}}$ was found so that we could perform an error analysis. Typically, however, the forward model is non-linear and the retrieval solution has to be found in an iterative manner. Hence, the question arises as to what the effect of including fluorescence emission as a fit parameter is on the stability of retrieval. We have carried out some preliminary tests that have indicated that retrieval is stable even when using starting values that strongly differ from true values.
Acknowledgements. This work has been performed within ESA's AEROPRO (AEROsol PROfile retrieval concept development and validation for Sentinel-4) project and within the TROPOMI national program funded by the Netherlands Space Office (NSO). We thank Yasjka Meijer and Ben Veihelmann from the AEROPRO team at ESA, and Piet Stammes, Ofelia Vieitez and Maarten Sneep at KNMI for useful discussions. A Fortran 77 code for line-mixing in the $\mathrm{O}_{2} \mathrm{~A}$ band, including the updates discussed in Tran and Hartmann (2008), was kindly provided by J.-M. Hartmann.

Edited by: A. Kokhanovsky

\section{References}

Amoros-Lopez, J., Gomez-Chova, L., Vila-Frances, J., Alonso, L., Calpe, J., Moreno, J., and Del Valle-Tascon, S.: Evaluation of remote sensing of vegetation fluorescence by the analysis of diurnal cycles, Int. J. Remote Sens., 29, 17-18, 5423-5436, doi:10.1080/01431160802036391, 2008.

Badayev, V. V. and Malkevich, M. S.: On the possibility of retrieval of aerosol extinction vertical profile using satellite observation of reflected radiation in the oxygen $760 \mathrm{~nm}$ band, Izvestia of the USSR Academy of Sciences, Atmos. Ocean. Phys., 14, 722-727, 1978.

Bodhaine, B. A., Wood, N. B., Dutton, E. G., and Slusser, J. R.: On Rayleigh Optical Depth Calculations, J. Atmos. Ocean. Tech., 16, 1854-1861, 1999.

Boesch, H., Baker, D., Connor, B., Crisp, D., and Miller, C.: Global Characterization of $\mathrm{CO}_{2}$ Column Retrievals from Shortwave-Infrared Satellite Observations of the Orbiting Carbon Observatory-2 Mission, Remote Sens., 3, 270-304, doi:10.3390/rs3020270, 2011.

Bovensmann, H., Burrows, J. P., Buchwitz, M., Frerick, J., Noël, S., Rozanov, V. V., Chance, K. V., and Goede, A. P. H.: SCIAMACHY: Mission objectives and measurement modes, J. Atmos. Sci., 56, 127-150, 1999.

Bovensmann, H., Buchwitz, M., Burrows, J. P., Reuter, M., Krings, T., Gerilowski, K., Schneising, O., Heymann, J., Tretner, A., and Erzinger, J.: A remote sensing technique for global monitoring of power plant $\mathrm{CO}_{2}$ emissions from space and related applications, Atmos. Meas. Tech., 3, 781-811, doi:10.5194/amt-3-781-2010, 2010.

Buchwitz, M., Reuter, M., Bovensmann, H., Pillai, D., Heymann, J., Schneising, O., Rozanov, V., Krings, T., Burrows, J. P., Boesch, H., Gerbig, C., Meijer, Y., and Löscher, A.: Carbon Monitoring Satellite (CarbonSat): assessment of scattering related atmospheric $\mathrm{CO}_{2}$ and $\mathrm{CH}_{4}$ retrieval errors and first results on implications for inferring city $\mathrm{CO}_{2}$ emissions, Atmos. Meas. Tech. Discuss., 6, 4769-4850, doi:10.5194/amtd-6-4769-2013, 2013.

Burrows, J. P., Weber, M., Buchwitz, M., Rozanov, V., LadstätterWeißenmayer, A., Richter, A., DeBeek, R., Hoogen, R., Bramstedt, K., Eichmann, K.-U., Eisinger, M., and Perner, D.: The Global Ozone Monitring Experiment (GOME): Mission Concept and First Scientific Results, J. Atmos. Sci., 56, 151-175, 1999.

Butz, A., Galli, A., Hasekamp, O., Landgraf, J., Tol, P., and Aben, I.: TROPOMI aboard Sentinel-5 Precursor: Prospective performance of $\mathrm{CH}_{4}$ retrievals for aerosol and cirrus loaded atmospheres, Remote Sens. Environ., 120, 267-276, doi:10.1016/j.rse.2011.05.030, 2012. 
Callies, J., Corpacciolli, E., Eisinger, M., Hahne, A., and Lefebvre, A.: GOME-2 - Metop's Second-Generation Sensor for Operational Ozone Monitoring, ESA Bulletin, 102, 28-36, 2000.

Caudill, T. R., Flittner, D. E., Herman, B. M., Torres, O., and McPeters, R. D.: Evaluation of the pseudo-spherical approximation for backscattered ultraviolet radiances and ozone retrieval, J. Geophys. Res., 102, 3881-3890, 1997.

Chance, K. and Kurucz, R. L.: An improved high-resolution solar reference spectrum for earth's atmosphere measurements in the ultraviolet, visible, and near infrared, J. Quant. Spectrosc. Ra., 111, 1289-1295, doi:10.1016/j.jqsrt.2010.01.036, 2010.

Corradini, S. and Cervino, M.: Aerosol extinction coefficient profile retrieval in the oxygen A-band considering multiple scattering atmosphere. Test case: SCIAMACHY nadir simulated measurements, J. Quant. Spectrosc. Ra., 97, 354-380, doi:10.1016/j.jqsrt.2005.05.061, 2006.

Crisp, D., Atlas, R. M., Breon, F.-M., Brown, L. R., Burrows, J. P., Ciais, P., Connor, B. J., Doney, S. C., Fung, I. Y., Jacob, D. J., Miller, C. E., O'Brien, D., Pawson, S., Randerson, J. T., Rayner, P., Salawitch, R. J., Sander, S. P., Sen, B., Stephens, G. L., Tans, P. P., Toon, G. C., Wennberg, P. O., Wofsy, S. C., Yung, Y. L., Kuang, Z., Chudasama, B., Sprague, G., Weiss, B., Pollock, R., Kenyon, D., and Schroll, S.: The Orbiting Carbon Observatory (OCO) Mission, Adv. Space Res., 34, 700-709, 2004.

Daniel, J. S., Solomon, S., Miller, H. L., Langford, A. O., Portmann, R. W., and Eubank, C. S.: Retrieving cloud information from passive measurements of solar radiation absorbed by molecular oxygen and $\mathrm{O}_{2}-\mathrm{O}_{2}$, J. Geophys. Res., 108, D164515, doi:10.1029/2002JD002994, 2003.

De Haan, J. F., Bosma, P. B., and Hovenier, J. W.: The adding method for multiple scattering calculations of polarized light, Astron. Astrophys., 183, 371-391, 1987.

Deschamps, P.-Y., Bréon, F.-M., Leroy, M., Podaire, A., Bricaud, A., Buriez, J.-C., and Sèze, G.: The POLDER mission: Instrument characteristics and scientific objectives, IEEE T. Geosci. Remote, 32, 1398-1411, 1994.

Dubovik, O., Holben, B., Eck, T. F., Smirnov, A., Kaufman, Y. J., King, M. D., Tanré, D., and Slutsker, I.: Variability of absorption and optical properties of key aerosol types observed in worldwide locations, J. Atmos. Sci., 59, 590-608, 2002.

Dubuisson, P., Frouin, R., Dessailly, D., Duforêt, L., Léon, J.-F., Voss, K., and Antoine, D.: Estimating the altitude of aerosol plumes over the ocean from reflectance ratio measurements in the $\mathrm{O}_{2}$ A-band, Remote Sens. Environ., 113, 1899-1911, doi:10.1016/j.rse.2009.04.018, 2009.

Dubuisson, P., Riedi, J., Ramon, D., Monsterleet, B., Pascal, N., Matusiak, S., and Lifermann, A.: Estimating aerosol altitude over ocean from $\mathrm{O}_{2}$ A-band absorption using MERIS observations, Proceedings of Advances in Atmospheric Science and Applications, Bruges, Belgium, 18-22 June 2012, 2012.

European Space Agency (ESA): ESA SP-1313/4 Candidate Earth Explorer Core Missions - Reports for Assessment: FLEX - Fluorescence EXplorer, ESTEC, Noordwijk, The Netherlands, available at: http://esamultimedia.esa.int/docs/SP1313-4_FLEX.pdf (last access: 26 March 2013), 2008.

European Space Agency (ESA): GMES Sentinels 4 and 5 Mission Requirements Traceability Document, issue 1, 20 September 2012, ESTEC, Noordwijk, The Netherlands, available at: http://esamultimedia.esa.int/docs/EarthObservation/S4_
5_5p_MRTD_issue_1.0_authorised.pdf (last access: 26 March 2013), 2012.

Frankenberg, C., Butz, A., and Toon, G. C.: Disentangling chlorophyll fluorescence from atmospheric scattering effects in $\mathrm{O}_{2}$ A-band spectra of reflected sun-light, Geophys. Res. Lett., 38, L03801, doi:10.1029/2010GL045896, 2011a.

Frankenberg, C., Fisher, J. B., Worden, J., Badgley, G., Saatchi, S. S., Lee, J.-E., Toon, G. C., Butz, A., Jung, M., Kuze, A., and Yokota, T.: New global observations of the terrestrial carbon cycle from GOSAT: Patterns of plant fluorescence with gross primary productivity, Geophys. Res. Lett., 38, L17706, doi:10.1029/2011GL048738, 2011b.

Frankenberg, C., O’Dell, C., Guanter, L., and McDuffie, J.: Remote sensing of near-infrared chlorophyll fluorescence from space in scattering atmospheres: implications for its retrieval and interferences with atmospheric $\mathrm{CO}_{2}$ retrievals, Atmos. Meas. Tech., 5, 2081-2094, doi:10.5194/amt-5-2081-2012, 2012.

Gabella, M., Kisselev, V., and Perona, G.: Retrieval of aerosol profile variations from reflected radiation in the oxygen absorption A band, Appl. Optics, 38, 3190-3195, 1999.

Guanter, L., Alonso, L., Gómez-Chova, L., Meroni, M., Preusker, R., Fischer, J., and Moreno, J.: Developments for vegetation florescence retrieval from spaceborne high-resolution spectrometry in the $\mathrm{O}_{2}-\mathrm{A}$ and $\mathrm{O}_{2}$-B absorption bands, J. Geophys. Res., 115, D19303, doi:10.1029/2009JD013716, 2010.

Guanter, L., Frankenberg, C., Dudhia, A., Lewis, P. E., GómezDans, J., Kuze, A., Suto, H., and Grainger, R. G.: Retrieval and global assessment of terrestrial chlorophyll fluorescence from GOSAT space measurements, Remote Sens. Environ., 121, 236251, doi:10.1016/j.rse.2012.02.006, 2012.

Hasekamp, O. P. and Butz, A.: Efficient calculation of intensity and polarization spectra in vertically inhomogeneous scattering and absorption atmospheres, J. Geophys. Res., 113, D20309, doi:10.1029/2008JD010379, 2008.

Hasekamp, O. and Siddans, R.: Aerosols (Chapter 8), in: CAMELOT Task 3 Report - Retrieval simulations, edited by: Veefkind, J. P., ESA Contract No. 21533/07/NL/HE, issue 1, 30 November 2009, 2009.

Hovenier, J. W., Van der Mee, C. V. M., and Domke, H.: Transfer of polarized light in planetary atmospheres; basic concepts and practical methods, Kluwer, Dordrecht, The Netherlands, 2004.

Ingmann, P., Veihelmann, B., Langen, J., Lamarre, D., Stark, H., and Bazalgette Courrèges-Lacoste, G.: Requirements for the GMES Atmosphere Service and ESA's implementation concept: Sentinels-4/5 and -5p, Remote Sens. Environ., 120, 58-69, doi:10.1016/j.rse.2012.01.023, 2012.

Joiner, J., Yoshida, Y., Vasilkov, A. P., Yoshida, Y., Corp, L. A., and Middleton, E. M.: First observations of global and seasonal terrestrial chlorophyll fluorescence from space, Biogeosciences, 8, 637-651, doi:10.5194/bg-8-637-2011, 2011.

Joiner, J., Vasilkov, A. P., Gupta, P., Bhartia, P. K., Veefkind, P., Sneep, M., De Haan, J., Polonsky, I., and Spurr, R.: Fast simulators for satellite cloud optical centroid pressure retrievals; evaluation of OMI cloud retrievals, Atmos. Meas. Tech., 5, 529-545, doi:10.5194/amt-5-529-2012, 2012a.

Joiner, J., Yoshida, Y., Vasilkov, A. P., Middleton, E. M., Campbell, P. K. E., Yoshida, Y., Kuze, A., and Corp, L. A.: Filling-in of near-infrared solar lines by terrestrial fluorescence and other geophysical effects: simulations and space-based observations from 
SCIAMACHY and GOSAT, Atmos. Meas. Tech., 5, 809-829, doi:10.5194/amt-5-809-2012, 2012b.

Joiner, J., Guanter, L., Lindstrot, R., Voigt, M., Vasilkov, A. P., Middleton, E. M., Huemmrich, K. F., Yoshida, Y., and Frankenberg, C.: Global monitoring of terrestrial chlorophyll fluorescence from moderate spectral resolution near-infrared satellite measurements: methodology, simulations, and application to GOME-2, Atmos. Meas. Tech. Discuss., 6, 3883-3930, doi:10.5194/amtd-6-3883-2013, 2013.

Koelemeijer, R. B. A., Stammes, P., Hovenier, J. W., and De Haan, J. F.: A fast method for retrieval of cloud parameters using oxygen A band measurements from the Global Ozone Monitoring Experiment, J. Geophys. Res., 106, 3475-3490, 2001.

Koelemeijer, R. B. A., De Haan, J. F., and Stammes, P.: A database of spectral surface reflectivity in the range 335-772 nm derived from 5.5 years of GOME observations, J. Geophys. Res., 108, D24070, doi:10.1029/2002JD002429, 2003.

Kokhanovsky, A. A. and Rozanov, V. V.: The determination of dust cloud altitudes from a satellite using hyperspectral measurements in the gaseous absorption band, Int. J. Remote Sens., 31, 27292744, doi:10.1080/01431160903085644, 2010.

Koppers, G. A. A. and Murtagh, D. P.: Retrieval of height resolved aerosol optical thickness in the atmospheric band (Chapter 5), in: G.A.A. Koppers, Radiative transfer in the absorption bands of oxygen: Studies of their significance in ozone chemistry and potential for aerosol remote sensing, Stockholm University, Stockholm, Sweden, 1997.

Kraft, S., Del Bollo, U., Harnisch, B., Bouvet, M., Drusch, M., and Bézy, J.-L.: Fluorescence Imaging Spectrometer concepts for the Earth Explorer Mission Candidate FLEX, Proceedings of International Conference on Space Optics, Ajaccio, Corse, 9-12 October 2012, 2012.

Krause, G. H. and Weis, E.: Chlorophyll fluorescence and photosynthesis: The basics, Annu. Rev. Plant Phys., 42, 313-349, 1991.

Kuze, A., Suto, H., Nakajima, M., and Hamazaki, T.: Thermal and near infrared sensor for carbon observation Fourier-transform spectrometer on the Greenhouse Gases Observing Satellite for greenhouse gases monitoring, Appl. Optics, 48, 6716-6733, 2009.

Landgraf, J., Hasekamp, O., Box, M., and Troutmann, T.: A linearized radiative transfer model for ozone profile retrieval using the analytical forward-adjoint perturbation approach, J. Geophys. Res., 106, 27291-27305, 2001.

Levy, R. C., Remer, L. A., Kleidman, R. G., Mattoo, S., Ichoku, C., Kahn, R., and Eck, T. F.: Global evaluation of the Collection 5 MODIS dark-target aerosol products over land, Atmos. Chem. Phys., 10, 10399-10420, doi:10.5194/acp-10-10399-2010, 2010.

Maxwell, K. and Johnson, G. N.: Chlorophyll fluorescence - a practical guide, J. Exp. Bot., 51, 659-668, 2000.

Meijer, Y., Ingmann, P., Löscher, A., Sierk, B., Bovensmann, H., and Buchwitz, M.: CarbonSat: ESA's Earth Explorer 8 Candidate Mission, Advances in Atmospheric Science and Applications, Bruges, Belgium, 18-22 June 2012, 2012.

O’Dell, C. W., Connor, B., Bösch, H., O’Brien, D., Frankenberg, C., Castano, R., Christi, M., Crisp, D., Eldering, A., Fisher, B., Gunson, M., McDuffie, J., Miller, C. E., Natraj, V., Oyafuso, F., Polonsky, I., Smyth, M., Taylor, T., Toon, G. C., Wennberg, P. O., and Wunch, D.: The ACOS $\mathrm{CO}_{2}$ retrieval algorithm - Part
1: Description and validation against synthetic observations, Atmos. Meas. Tech., 5, 99-121, doi:10.5194/amt-5-99-2012, 2012.

Rast, M., Bézy, J. L., and Bruzzi, S.: The ESA medium resolution imaging spectrometer MERIS: A review of the instrument and its mission, Int. J. Remote Sens., 20, 1681-1702, 1999.

Reuter, M., Buchwitz, M., Schneising, O., Heymann, J., Bovensmann, H., and Burrows, J. P.: A method for improved SCIAMACHY $\mathrm{CO}_{2}$ retrieval in the presence of optically thin clouds, Atmos. Meas. Tech., 3, 209-232, doi:10.5194/amt-3-209-2010, 2010.

Rodgers, C. D.: Inverse methods for atmospheric sounding: Theory and Practice, World Scientific Publishing, Singapore, 2000.

Rozanov, V. V. and Kokhanovsky, A. A.: Semianalytical cloud retrieval algorithm as applied to the cloud top altitude and the cloud geometrical thickness determination from top-of-atmosphere reflectance measurements in the oxygen A band, J. Geophys. Res., 109, D05202, doi:10.1029/2003JD004104, 2004.

Salstein, D. A., Ponte, R. M., and Cady-Pereira, K.: Uncertainties in atmospheric pressure fields from global analyses, J. Geophys. Res., 113, D14107, doi:10.1029/2007JD009531, 2008.

Sanders, A. F. J., De Haan, J. F., and Veefkind, J. P.: Retrieval of aerosol height from the oxygen A band with TROPOMI, in: Proceedings of Advances in Atmospheric Science and Applications, Bruges, Belgium, 18-22 June 2012, 2012.

Sanghavi, S., Martonchik, J. V., Landgraf, J., and Platt, U.: Retrieval of optical depth and vertical distribution of particulate scatterers in the atmosphere using $\mathrm{O}_{2}$ A- and B-band SCIAMACHY observations over Kanpur: a case study, Atmos. Meas. Tech., 5, 1099-1119, doi:10.5194/amt-5-1099-2012, 2012.

Seidel, F. C. and Popp, C.: Critical surface albedo and its implications to aerosol remote sensing, Atmos. Meas. Tech., 5, 16531665, doi:10.5194/amt-5-1653-2012, 2012.

Siddans, R., Latter, B. G., and Kerridge, B. J.: Study to Consolidate the UVS Mission Requirements for the Oxygen A-band, EUMETSAT Contract No. EUM/CO/05/1411/SAT, version 1.2, 24 May 2007, available at: www.eumetsat.int/Home/Main/ Satellites/MeteosatThirdGeneration/Resources/Index.htm (last access: 26 March 2013), 2007.

Sioris, C. E., Bazalgette Courrèges-Lacoste, G., and Stoll, M.-P.: Filling in of Fraunhofer lines by plant fluorescence: Simulations for a nadir-viewing satellite-borne instrument, J. Geophys. Res., 108, D44133, doi:10.1029/2001JD001321, 2003.

Tran, H. and Hartmann, J.-M.: An improved $\mathrm{O}_{2}$ A band absorption model and its consequences for retrievals of photon paths and surface pressure, J. Geophys. Res., 113, D18104, doi:10.1029/2008JD010011, 2008.

Tran, H., Boulet, C., and Hartmann, J.-M.: Line mixing and collision-induced absorption by oxygen in the A band: Laboratory measurements, model, and tools for atmospheric spectra computations, J. Geophys. Res., 111, D15210, doi:10.1029/2005JD006869, 2006.

van Diedenhoven, B., Hasekamp, O. P., and Aben, I.: Surface pressure retrieval from SCIAMACHY measurements in the $\mathrm{O}_{2} \mathrm{~A}$ Band: validation of the measurements and sensitivity on aerosols, Atmos. Chem. Phys., 5, 2109-2120, doi:10.5194/acp-5-21092005, 2005.

Vasilkov, A., Joiner, J., and Spurr, R.: Note on rotational-Raman scattering in the $\mathrm{O}_{2}$ A- and B-bands, Atmos. Meas. Tech., 6, 981-990, doi:10.5194/amt-6-981-2013, 2013. 
Veefkind, J. P., Aben, I., McMullan, K., Förster, H., De Vries, J., Otter, G., Claas, J., Eskes, H. J., De Haan, J. F., Kleipool, Q., Van Weele, M., Hasekamp, O., Hoogeveen, R., Landgraf, J., Snel, R., Tol, P., Ingmann, P., Voors, R., Kruizinga, B., Vink, R., Visser, H., and Levelt, P. F.: TROPOMI on the ESA Sentinel-5 Precursor: A GMES mission for global observations of the atmospheric composition for climate, air quality and ozone layer applications, Remote Sens. Environ., 120, 70-83, doi:10.1016/j.rse.2011.09.027, 2012.
Wang, P., Tuinder, O. N. E., Tilstra, L. G., and Stammes, P.: Interpretation of FRESCO cloud retrievals in case of absorbing aerosol events, Atmos. Chem. Phys., 12, 9057-9077, doi:10.5194/acp-12-9057-2012, 2012.

Yoshida, Y., Ota, Y., Eguchi, N., Kikuchi, N., Nobuta, K., Tran, H., Morino, I., and Yokota, T.: Retrieval algorithm for $\mathrm{CO}_{2}$ and $\mathrm{CH}_{4}$ column abundances from short-wavelength infrared spectral observations by the Greenhouse gases observing satellite, Atmos. Meas. Tech., 4, 717-734, doi:10.519/amt-4-717-2011, 2011. 